\title{
PROJECT RISK EVALUATION BY USING A NEW FUZZY MODEL BASED ON ELENA GUIDELINE
}

\author{
Pezhman ASADI ${ }^{1}$, Javad REZAEIAN ZEIDI ${ }^{2}$, Toraj MOJIBI ${ }^{3}$, \\ Abdolreza YAZDANI-CHAMZINI ${ }^{4}$, Jolanta TAMOŠAITIENE $5^{* *}$ \\ ${ }^{1}$ Department of Executive Management, Faculty of Management, Islamic Azad University, \\ Firuzkouh Branch, Tehran, Iran \\ ${ }^{2}$ Department of Industrial Engineering, Mazandaran University of Science and Technology, Mazandaran, Iran \\ ${ }^{3}$ Department of Management, Islamic Azad University, Firuzkouh Branch, Tehran, Iran \\ ${ }^{4}$ Young Researchers and Elite Club, South Tehran Branch, Islamic Azad University, Tehran, Iran \\ ${ }^{5}$ Faculty of Civil Engineering, Vilnius Gediminas Technical University, \\ Sauletekio al. 11, LT-10223 Vilnius, Lithuania
}

Received 17 February 2018; accepted 21 May 2018

\begin{abstract}
The complexity and dynamics of the executive projects have coped contractors with substantial hazards and losses. Project risk management is a critical tool for authority to improve its performance and secure the success of the organization. However, a number of standards and approaches have been developed to formulate the projects based on their risks. The Elena guideline is a systematic standard developed by Iran Project Management Association. This guideline provides the full cycle of the risk management process. Risk evaluation is the key part of the risk management process. On the other hand, different techniques have been developed to model a risk evaluation problem. Fuzzy inference system is one of the most popular techniques that is capable of handling all types of the uncertainty involved in projects. This paper proposes a three-stage approach based on the fuzzy inference system under the environment of the Elena guideline to cope with the risky projects. Finally, an illustrative example of the risk evaluation is presented to demonstrate the potential application of the proposed model. The results show that the proposed model evaluates the risky projects efficiently and effectively.
\end{abstract}

Keywords: project risk evaluation, Rah Gostar Naft Company, fuzzy inference system, Elena guideline.

\section{Introduction}

A typical project is known as a unique system and often, by its nature, is as a sophisticated organization that generally takes place over a prolonged period of time. It employs a wide range of resources, comprising materials, facilities, human, and finance, to achieve a particular aim. According to the statistical data reported by El-Razek et al. (2008), the risks involved in the project can lead to an increase to $100 \%$ of the anticipated cost of the project. As well as Moura et al. (2007) declared, that the project risks may increase the time and cost by $40 \%$ and $12 \%$, respectively. Omoregie and Radford (2006) found that the time and cost overruns are $188 \%$ and $14 \%$, respectively. On the other hand, only $33.35 \%$ and $37.2 \%$ of the private sector projects and $20.5 \%$ and $46.8 \%$ of the public sector projects were completed within the estimated time and cost, respectively (Endut et al. 2009). Based on the Pareto's law, $20 \%$ of the elements effect $80 \%$ of the outcome; so that, a manager should identify a small percentage of most critical components, resulting in the largest percentage of adverse consequences (Tseng et al. 2005).

The main objective of a risk analysis process is to minimize the unknown risks that have adverse impacts on the project and maximize the opportunities that lead to a significant increase in the profits of the project. This analysis helps a project manager to properly allocate resources by risk ranking process and effectively implement the risk reduction scenarios. This analysis provides insight and understanding for better decision making in order to facilitate more profitable business. This can lead to a systematic approach to preventing a project from violent fluctuation

*Corresponding author. E-mail: jolanta.tamosaitiene@vgtu.lt 
by risk reduction measures. However, without a robust risk analysis, a project may have wide-ranging negative implications for the achievement of organizational objectives (Cooper et al. 2005).

According to the important role of project risk management, different approaches by the professional project management associations and many government agencies have been developed to accurately model the risks imposed by a typical project. In the USA, Project Management Institute (PMI) provided a risk management program to systematically manage the risks of projects (PMI 2003). In the UK, Association for Project Management developed the Project Risk Analysis and Management (PRAM) guide to scientifically monitor the risks of projects (Chapman 1997). Standards Association of Australia introduced a risk management guideline for risk analysis (AS/NZS 4360 2004). International Electrotechnical Commission (IEC) provided a general introduction to project risk management, its sub-processes, and influencing factors (IEC 62198 2001). Office of Government Commerce (OGC) developed a route map for risk management (OGC 2002). The approach developed by OGC (2002) helps managers to identify, assess, and control risks. Treasury Board of Canada (TBC) provided an integrated risk management framework that is an effective framework for making informed decisions (TBC 2001). However, often approaches offer few insights into how the process of risk management works in practice. Therefore, Iran project management association developed a new approach that is known as Elena guideline, more adapted to the country conditions, to comprehensively manage a typical project. This guideline provides a practical guidance for conducting the effective risk management process. This process comprises five main parts, including risk determination, risk identification, risk evaluation, risk planning, and risk monitoring. Nevertheless, the risk evaluation is the core part of the risk management process. According to the key importance of the risk evaluation, a large number of models have been developed to effectively formulate the potential risks imposed by projects.

Tüysüz and Kahraman (2006) provided a model for the project risk evaluation under an incomplete and vague environment. They used the fuzzy analytic hierarchy process (AHP) method as an effective way of evaluating project risks based on the heuristic knowledge of experts to evaluate the riskiness of an information technology project. Badri et al. (2012) employed a systematic approach to the evaluation of occupational, health, and safety risks. They utilized the number of risk factors and corresponding relative significance to form a new procedure.

Zeng et al. (2007) presented an effective tool based on fuzzy reasoning and modified analytical hierarchy process techniques for risk assessment to cope with risks in complicated construction situations. They applied the fuzzy reasoning technique to formulate the uncertainties and subjectivities. Dey (2002) combined the AHP technique with decision tree analysis to develop a quantitative approach for construction risk management. Liu et al. (2011) proposed a risk evaluation method based on an uncertain linguistic for a high-tech project investment. Fouladgar et al. (2012) developed a new combination model based on the fuzzy TOPSIS technique to evaluate the risks involved in the tunneling construction projects. A methodology designed for internal project management in small firms is presented by Marcelino-Sádaba et al. (2014).

Nieto-Morote and Ruz-Vila (2011) presented a combination risk assessment model based on the AHP and fuzzy logic techniques. They used the AHP technique to structure a large number of risks and the fuzzy logic to cope with subjective judgement. A combination model based on the failure modes and effects analysis and the AHP method under fuzzy environment is developed by $\mathrm{Hu}$ et al. (2009) to evaluate the risks of green components. Dey (2010) developed a conceptual risk management framework based on risk map and the AHP technique for project risk management. Vrijling et al. (1995) developed a practical framework for risk evaluation. Xu et al. (2010) developed a fuzzy synthetic evaluation model for assessing the risk level of a particular critical risk group and the overall risk level associated with PPP projects in China.

Hillson et al. (2006) used the risk breakdown matrix, using the risk break-down structure and work breakdown structure, to develop a method for project risk management. Liu et al. (2012) proposed a model for risk evaluation and criticality analysis in an intuitive manner. They combined the FMEA method with the VIKOR technique under a fuzzy environment to use the linguistic variables for ratings and weighing the risk factors. As well as, they employed the VIKOR technique for determining the risk priorities of the failure modes. Dey (2012) employed decision tree analysis and multiple criteria decision-making technique to propose an integrated analytical framework for effective management of project risks.

Iqbal et al. (2015) accomplished a questionnaire-based survey on risk management in construction projects in $\mathrm{Pa}$ kistan. They declared that preparation of a proper schedule and good coordination during the implementation stage may help project managers to focus on critical areas for better management of projects in Pakistan. Akintoye and MacLeod (1997) developed a risk analysis model in construction by using a questionnaire-based survey of general contractors and project management practices. They concluded that risk management is essential to construction activities in minimizing losses and enhancing profitability. Tah and Carr (2000) developed a formal model for qualitative risk assessment by using a hierarchical risk breakdown structure representation. Carbone and Tippett (2004) proposed a model for project risk analysis by using an extension of the failure mode and effects analysis. Chapman (1990) developed a model based on the probabilistic distribution to project risk management. Cano and Cruz (2002) presented a generic project risk management process.

Zou and Zhang (2009) proposed a model based on project stakeholder and life cycle for providing an alternative way to scrutinize the risks associated with construction 
projects. Wang et al. (2004) developed a risk management framework for project risk evaluation and corresponding effective mitigation measures. Tamošaitienè et al. (2008) presented modeling of contractor selection taking into account different risk level. Carvalho and Junior (2015) elucidated the relationship between project success and risk management. Zavadskas et al. $(2008,2010)$, Tamošaitienè et al. (2013), Chatterjee et al. (2018) presented a risk assessment model based on the multi-attribute decisionmaking methods for construction projects. Schieg (2006) developed a model for risk management in construction projects. Jamshidi et al. (2013) developed an application of the fuzzy logic for modeling the pipeline risk assessment. Razani et al. (2013) employed the fuzzy inference system to predict the roof fall rate for evaluating the risk of roof fall.

Valipour et al. (2016) developed a quantitative approach based on the fuzzy method and cybernetic analytic network process for equitable risk allocation with attention to identifying dependencies between risk allocation criteria and barriers. Yazdani-Chamzini (2014) proposed a risk assessment model based on the concepts of fuzzy set theory to evaluate the risk events during the tunnel construction operations. Rikhtegar et al. (2014) proposed a methodology based on analytic network process and fuzzy simple additive weight to formulate the environmental risks pertaining to mining projects. Yazdani-Chamzini et al. (2013) employed a combination of the fuzzy logic and the ELECTRE technique for risk evaluation in the tunnel construction projects. Liu et al. (2013) proposed a fuzzy synthetic evaluation approach for scientific drilling project risk assessment.

Ilbahar et al. (2018) developed a novel integrated approach based on Pythagorean fuzzy proportional risk assessment, including Fine Kinney, Pythagorean fuzzy analytic hierarchy process, and a fuzzy inference system. Ebrat and Ghodsi (2014) employed an ANFIS model to assess construction project risk. Keramati et al. (2013a) used fuzzy analytic hierarchy process to evaluate CRM risk factors based on active project managers' judgments. Keramati et al. (2013b) used the fuzzy analytical network process for prioritizing of risk factors based on experts' judgments. Samadi et al. (2014) employed the fuzzy analytic network process to prioritize risk factors and applied the fuzzy TOPSIS technique to prioritize the responses to these risk factors.

Nevertheless, often aforementioned models use the probabilistic distribution to evaluate a system or sub-system. On the other hand, uncertainty is an inevitable part of a risk assessment process that leads to an imprecise prediction of future conditions (Lee, Jones 2004). As well as, some uncertainties such as socio-economic changes may accumulate in the future and lead to a non-probabilistic pattern. Shroder and Davies (2015) showed that a risk analysis process by using the probabilistic approach requires a large number of data. They demonstrated with a sample size of 100 , the error is approximately $\pm 10 \%$; whereas, with a sample size of 10 , the error is about $\pm 40 \%$; and, as a result, with a sample size of 2 , the error is $\pm 95 \%$. Nowadays, the business activities are less repetitive due to the rise in customer power, the internationalization of the economic environment, and the rapid changes in the competitive climate (Loch et al. 2006). Therefore, it can be lead to an inefficient probability distribution. Therefore, it is inappropriate to make an attempt to create the probability distributions or models (Lee, Jones 2004).

However, a number of models neglect the uncertainty imposed by the unavailable data or incomplete information. Likewise, although some models take into account the inherent uncertainty resulted from less or lack of information and ill-defined knowledge, the all presented models ignore the uncertainty involved in the process of modeling. The main aim of the paper is to develop a new approach for risk evaluation of projects by using a threestep procedure. This procedure is a key for the promotion of portfolio performance.

The main aim of the paper is to develop a new model for risk evaluation of projects under the Elena guideline in the term of linguistic variables. The model is developed based on a combination of two tangible and intangible parameters, considering not only quantitative components in the terms of linguistic variables, but also considers qualitative parameters. This model is adapted to the atmosphere of business in Iran. This procedure, using a three-stage approach, is a key for the promotion of portfolio performance.

\section{Elena risk management guideline}

The Elena guideline, developed between 2001 and 2014 by Yakhchali (2014), to provide a simple risk model in order to manage the projects based on a practical tool. This guideline includes different parts of project management, comprising project organizational structure, project scheduling, project quality, project risk management, project event, project communications, project procurement, and project progress. The purpose of project risk management is to obtain better project outcomes, in terms of schedule, cost, and quality (Hashemi et al. 2011).

However, the effective implementation of risk management is part of best business practice. The approach proposed by the Elena guide shows how to determine, identify, analyze, evaluate, communicate, and monitor risks (see Figure 1). This guideline provides a systematic and practical approach to evaluate the risks imposed by projects. This approach, a generic risk evaluation standard, is readily employed for project risk management. This method defines a step-by-step methodology for risk evaluation process. This method provides an operational framework for a wide range of organizations, including voluntary organizations, non-government organizations, partnerships, commercial enterprises, and public sector entities. The difference between the Elena guideline with the BMBOK and Prince2 standards is presented in Table 1. The risk evaluation approach developed by the Elena guideline provides a reference for managers and senior executives 


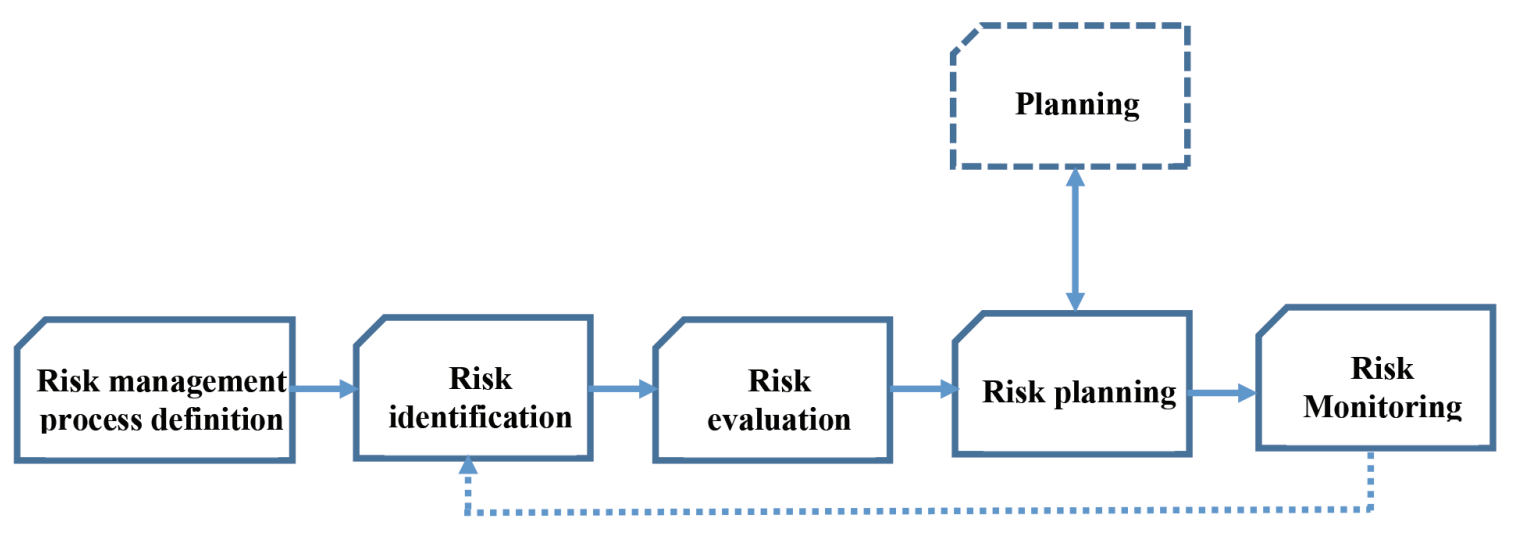

Figure 1. Schematic diagram of the Elena risk management

to evaluate the projects based on their risks. Generally, the main objectives of the project risk evaluation are to: (i) improve the capability of the organization, (ii) enhance the organization performance, (iii) reduce the potential hazards and negative consequences, and (iv) diminish the costs and threats associated with the risky projects.

\section{Fuzzy inference system}

Fuzzy set theory, an extension of the classical set, is first introduced by Zadeh (1965) to handle the inherent uncertainty and complexity involved in a typical problem. A fuzzy set can be described as a set with a flexible linguistic boundary instead of a classical sharp one. A fuzzy set employs membership functions to define the degree of membership of elements ranging from 0 to 1 . Fuzzy Logic is a powerful tool to treat natural phenomena and quantities in a logical way (Licata 2012).

The fuzzy set theory follows an organized and efficient approach to face with linguistic values. This method ful-

Table 1. Difference between Elena guideline with PMBOK and Prince2

\begin{tabular}{|l|c|c|c|}
\hline \multicolumn{1}{|c|}{ Property } & $\begin{array}{c}\text { Elena } \\
\text { guideline }\end{array}$ & $\begin{array}{c}\text { PMBOK } \\
\text { standard }\end{array}$ & $\begin{array}{c}\text { Prince2 } \\
\text { standard }\end{array}$ \\
\hline Knowledge base & $\checkmark$ & $\checkmark$ & $\mathbf{x}$ \\
\hline Methodology & $\checkmark$ & $\mathbf{x}$ & $\checkmark$ \\
\hline Comprehensive document & $\checkmark$ & $\mathbf{x}$ & $\mathbf{x}$ \\
\hline Various application areas & $\checkmark$ & $\checkmark$ & $\mathbf{x}$ \\
\hline Proportionment capability & $\checkmark$ & $\checkmark$ & $\checkmark$ \\
\hline $\begin{array}{l}\text { Portfolio and plan } \\
\text { management }\end{array}$ & $\checkmark$ & $\checkmark$ & $\checkmark$ \\
\hline $\begin{array}{l}\text { Coordination and } \\
\text { adopted to portfolio and } \\
\text { plan management }\end{array}$ & $\checkmark$ & $\mathbf{x}$ & $\mathbf{x}$ \\
\hline $\begin{array}{l}\text { Adapted to the } \\
\text { atmosphere of business } \\
\text { in Iran }\end{array}$ & $\checkmark$ & $\mathbf{x}$ & $\mathbf{x}$ \\
\hline $\begin{array}{l}\text { Availability of developed } \\
\text { group }\end{array}$ & $\checkmark$ & $\mathbf{x}$ & $\mathbf{x}$ \\
\hline
\end{tabular}

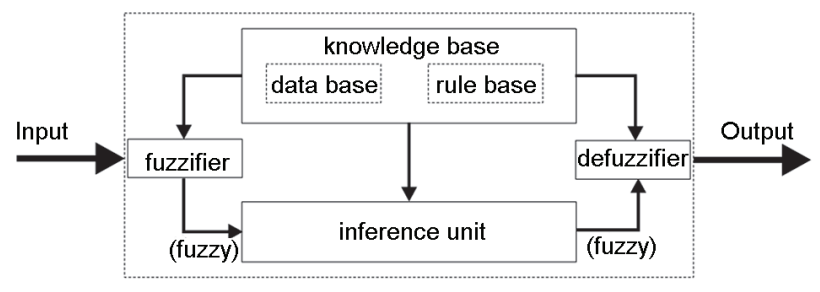

Figure 2. A typical fuzzy inference system

fills numerical computations by applying linguistic labels stipulated by membership functions (Razani et al. 2013).

This technique can combine expert's knowledge with numerical data to form a rule-based model for formulating the behavior of a typical system. A typical fuzzy inference process contains four main components, including fuzzification process, fuzzy rule base, fuzzy inference process, and defuzzification process as depicted in Figure 2.

Based on the basic concepts of the fuzzy set theory, the fuzzification process is applied to generate membership values for a fuzzy variable by using the membership functions. The shape of the membership functions depends on the nature of the problem under consideration that may be linear (trapezoidal or triangular) or non-linear. The fuzzification process transforms the crisp numerical values of input variables into corresponding fuzzy ones.

However, a rule-based system generally assumes that there are independent relationships among all input variables as depicted in Figure 3. From the figure, it can be obvious that the main difference between fuzzy and crisp systems is pertaining to the rule partition of an input space. A fuzzy rule-based system formulates the complex structure involved in data based on the assumption that the changes are not sudden but gradual in real-world problems. The fuzzy system uses the overlapping regulation, defined by membership functions, to change from one specific rule to others. A typical fuzzy if-then rule contains two main parts, including the first if part known as the antecedent and the rest then part known as the consequent. The number of if-then rules depends on the number of inputs and outputs, and the desired behavior of the system. The If-Then rules, establishing the knowledge base, are known as the fundamental elements of a fuzzy-based model. 


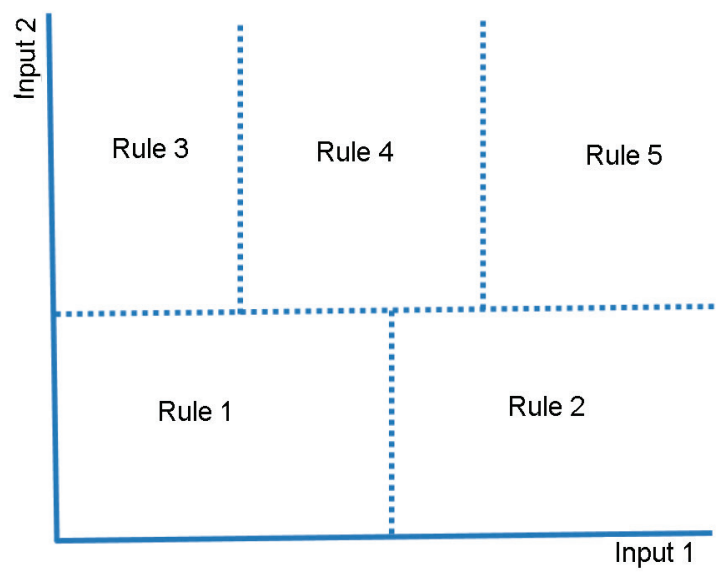

(a)

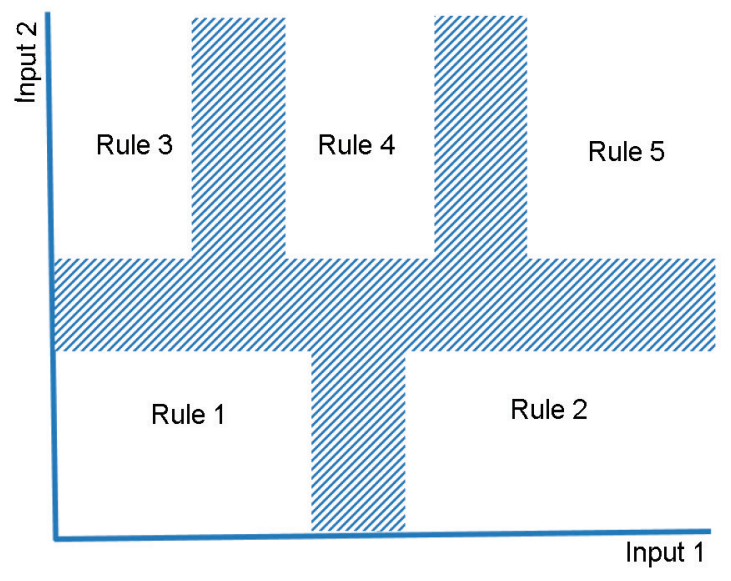

(b)

Figure 3. Rule partition of an input space: (a) partition for crisp rules and (b) partition for fuzzy rules

Fuzzy inference is the process of mapping the given input variables to an output space. Generally, three types of fuzzy inference algorithm are commonly developed, including Mamdani, Takagi-Sugeno, and Tsukamoto fuzzy algorithms. All algorithms are the same in the antecedent part. Whereas, they are different in the consequent part. In the Mamdani algorithm, the consequent of each rule is defined by a fuzzy set. The overall output is obtained by an aggregation and defuzzification process. Whereas, a typical Takagi-Sugeno algorithm uses a polynomial function based on the input variables to define the consequent of each rule. The overall output for this algorithm is obtained by a weighting mechanism. The Tsukamoto algorithm employs a fuzzy set with a monotonical membership function to define the consequent of each rule. The overall output is extracted from a weighted average process. Figure 4 depicts the reasoning procedure for three fuzzy inference algorithms. However, the Mamdani algorithm is more adaptable with human inputs. Therefore, this paper employs the Mamdani algorithm to formulate the problem of project risk evaluation.

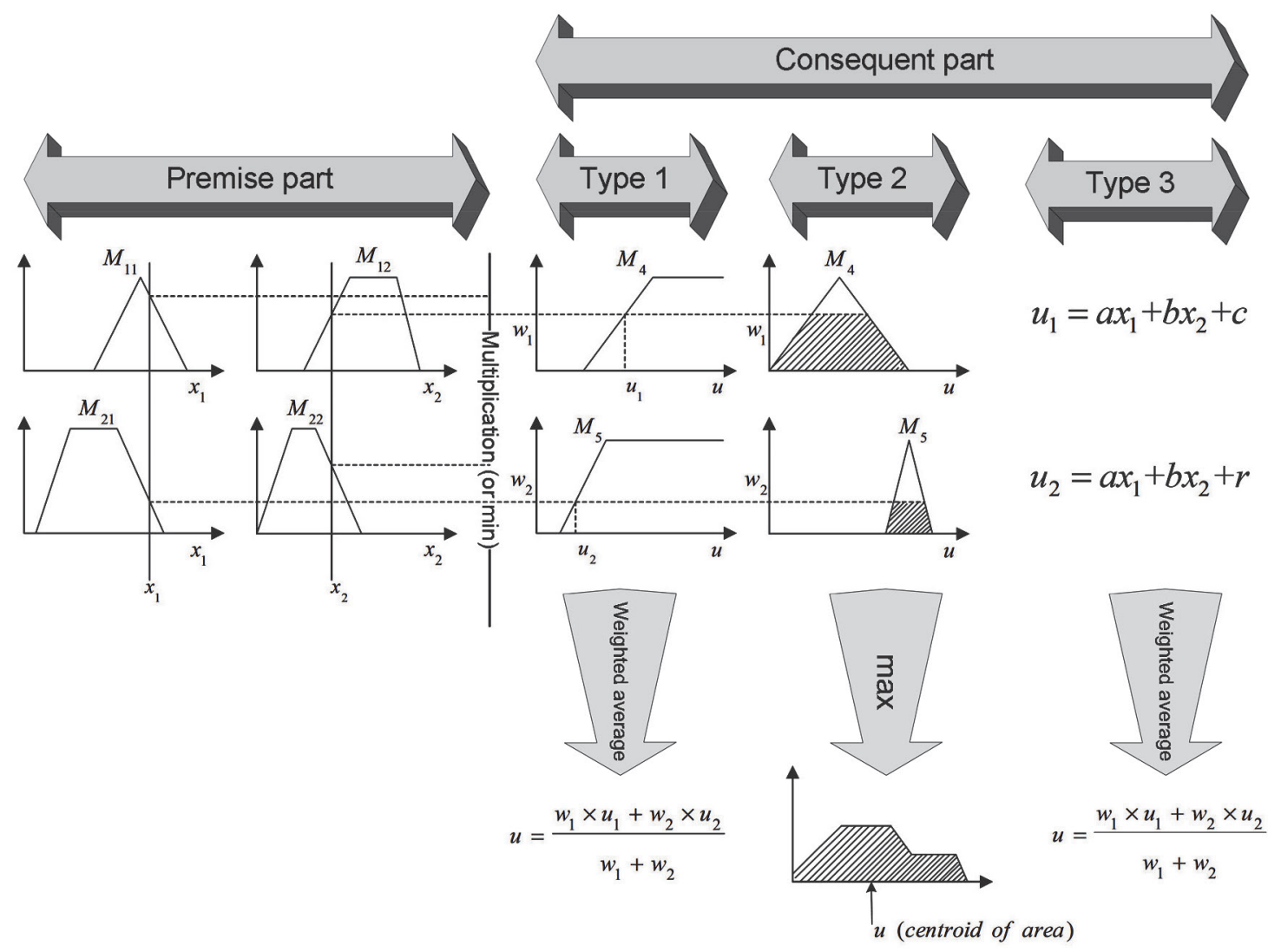

Figure 4. Fuzzy inference algorithms, including Tsukamoto (Type 1), Mamdani (Type 2), and Takagi-Sugeno (Type 3) 
However, the results obtained from the inference process are fuzzy values. Hence, the results of the fuzzy risk evaluation are translated into crisp values for further numerical analysis by a defuzzification process. Different defuzzification techniques have been developed, including centroid of area, mean of maximum, smallest of maximum, largest of maximum, and bisector of area. The selection of the defuzzification method depends on the application. In this study, the centroid of area (COA) method is applied for the defuzzification process.

\section{The proposed model for project risk evaluation}

The proposed model for the risk evaluation of projects based on the Elena guideline comprises a three-stage procedure, including vulnerability assessment, consequence assessment, and the overall risk evaluation. All stages use the fuzzy reasoning to cope with the inherent uncertainty imposed by projects. The unique feature of the model is to integrate both qualitative and quantitative techniques in the form of a systematic approach. Likewise, the model takes into account all types of uncertainties, including the uncertainty resulted from less or lack of information and the uncertainty arisen from the process of formulation. This leads to a more accurate evaluation of the potential risks associated with the projects under investigation. For better understanding, the framework of the proposed model is graphically shown in Figure 5.

The first stage concentrates on the vulnerability assessment, where three parameters the contribution rate (the ratio of the project value to all assets), resilience, and resistance play significant roles in the assessment

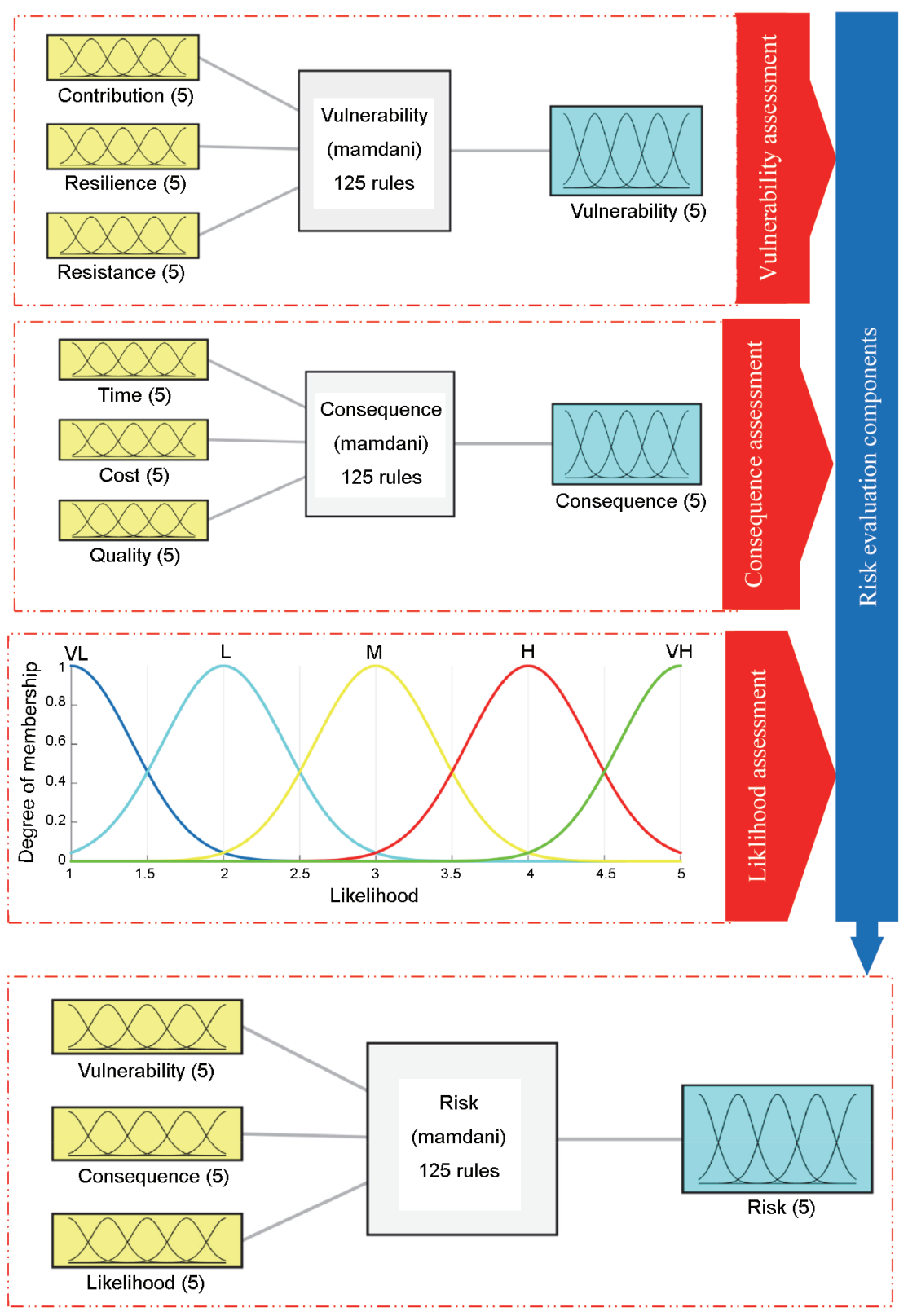

Figure 5. Schematic diagram of the model proposed for project risk evaluation 
process. The vulnerability can be defined as the susceptibility of an element to a dangerous phenomenon that is often associated with the loss of human and financial resource. This factor shows that how an element is exposed to damage. In this stage, the project potential for all dangers is calculated that is subtly different from the likelihood. In order to construct the fuzzy model for the vulnerability assessment, MATLAB software package is employed to assess the project potential for damage. The second stage focuses on all adverse consequences of a project. This stage uses time, cost, and quality impacts to assess the overall adverse consequence of selecting a project. In this stage, a fuzzy model for the consequence assessment is constructed in MATLAB software package. The last stage computes the final risk evaluation based on a combination of the outputs derived from two previous stages (vulnerability and consequence assessments) and the output resulted from experts' opinion (likelihood assessment). In this stage, the overall risk evaluation is determined to select a proper decision strategy for obtaining a more profitable outcome. After evaluation the project risks, the riskiest projects are eliminated and the projects with minimum risk are selected as the on-going operational projects.

\section{Case study: Rah Gostar Naft Company}

Rah Gostar Naft (RGF) Company, an Iranian company founded in the year 1999 by the Oil Industry Investment Companies (OIIC) group, is among the most popular companies in the field of oil, gas, industry, building and construction, road and transportation, and water resources in the country. The company business covers the whole of the supply chain, from production to product marketing and trading. The underlying reason for action in different fields is a significant increase in profits and competitive strength. The main aim is to apply the existing excess capacity. Therefore, the managers face with some problems in formulating the working policy on project selection, including the identification of the feasible projects, the evaluation of the projects and the selection of the best ones, and the launch of a new project in an organized way that can lead to a strong chance of success. In an ever-changing world, the RGF Company is fast changing with fluctuations. However, in a multi-product company, the process of the risk management is a critical activity to conduct a comprehensive analysis before selecting one or more specific project(s) in order to maximize the profits and opportunities and minimize the risks and threats.

\section{Implementation of the proposed model}

Based on the principal concepts of the Elena guideline, the first step is to define the risk management process. The main objective of this step is to show how the risk management processes will be executed. This step helps authorities to integrate the project risk management with asset management. After defining the risk management process, all the risks imposed by each project should be identified. For achieving the aim, a number of face-toface interviews with professional experts, among the most popular ways to identify the risky projects, are conducted. Therefore, a set of questions are asked from interviewees to present their own perspective. In the last phase of the second step, seven projects with minimum risk to organization objectives are identified by professional experts. After identifying the projects with minimum risk, the risk evaluation process is executed. Therefore, the proposed model is implemented as follows to evaluate the projects based on the risk to organization objectives.

The first key phase of the risk evaluation procedure is to collect the data by gathering and pre-processing the raw data. The data collection process helps authorities to generate the fuzzy rules and knowledge base that will be used as inputs in the subsequent phase. The raw data is typically resulted from both objective and subjective data. The subjective data is a qualitative estimate made by a professional expert in the form of an analytical and observational process and the objective data is a quantitative value extracted from an experimental, mathematical, and practical process. After data gathering, the proposed model is constructed. The model comprises three main stages. The first stage uses three components, containing the contribution rate, resilience, and resistance, to assess the vulnerability index. The second stage employs three factors, including time, cost, and quality, to assess the consequence index. Then, the outputs of the two previous stages are redefined by fuzzy sets and combined with the likelihood index obtained from experts' opinion to compute the risk value. Each stage is clearly explained and the outputs are comprehensively presented in the following sub-sections.

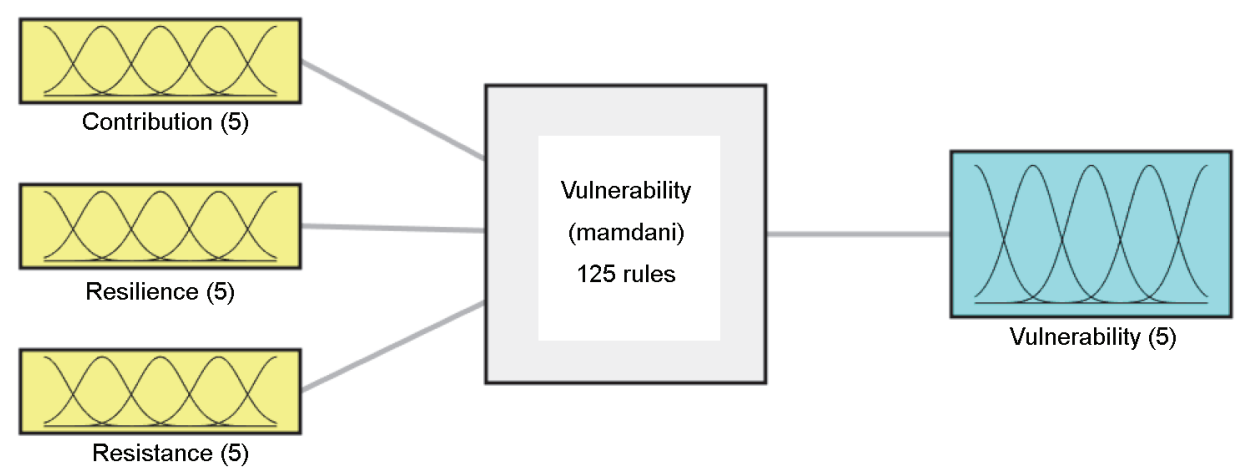

Figure 6. Structure of fuzzy model for vulnerability assessment 
Table 2. Fuzzy definition of input and output variables for the vulnerability assessment

\begin{tabular}{|c|c|c|c|}
\hline Factors & Linguistic term & Fuzzy ratings & $\begin{array}{l}\text { Universe of discourse } \\
\text { (X) }\end{array}$ \\
\hline \multirow[t]{5}{*}{ Contribution rate } & Very High (VH) & $3.5 \leq$ Contribution $\leq 5$ & \multirow[t]{5}{*}{$\mathrm{X}_{\text {Contribution }} €(1,5)$} \\
\hline & $\operatorname{High}(\mathrm{H})$ & $2.5 \leq$ Contribution $\leq 5$ & \\
\hline & Medium (M) & $1.5 \leq$ Contribution $\leq 4.5$ & \\
\hline & Low (L) & $1 \leq$ Contribution $\leq 3.5$ & \\
\hline & Very Low (VL) & $1 \leq$ Contribution $\leq 2.5$ & \\
\hline \multirow[t]{5}{*}{ Resilience } & Very High (VH) & $3.5 \leq$ Resilience $\leq 5$ & \multirow[t]{5}{*}{$\mathrm{X}_{\text {Resilience }} €(1,5)$} \\
\hline & High $(\mathrm{H})$ & $2.5 \leq$ Resilience $\leq 5$ & \\
\hline & Medium (M) & $1.5 \leq$ Resilience $\leq 4.5$ & \\
\hline & Low (L) & $1 \leq$ Resilience $\leq 3.5$ & \\
\hline & Very Low (VL) & $1 \leq$ Resilience $\leq 2.5$ & \\
\hline \multirow[t]{5}{*}{ Resistance } & Very High (VH) & $3.5 \leq$ Resistance $\leq 5$ & \multirow[t]{5}{*}{$\mathrm{X}_{\text {Resistance }} €(1,5)$} \\
\hline & High $(\mathrm{H})$ & $2.5 \leq$ Resistance $\leq 5$ & \\
\hline & Medium (M) & $1.5 \leq$ Resistance $\leq 4.5$ & \\
\hline & Low (L) & $1 \leq$ Resistance $\leq 3.5$ & \\
\hline & Very Low (VL) & $1 \leq$ Resistance $\leq 2.5$ & \\
\hline \multirow[t]{5}{*}{ Vulnerability } & Very high (VH) & $0.7 \leq$ Vulnerability $\leq 1.0$ & \multirow[t]{5}{*}{$\mathrm{X}_{\text {Vulnerability }} €(0,1)$} \\
\hline & High $(\mathrm{H})$ & $0.4 \leq$ Vulnerability $\leq 1.0$ & \\
\hline & Medium (M) & $0.2 \leq$ Vulnerability $\leq 0.8$ & \\
\hline & Low (L) & $0.0 \leq$ Vulnerability $\leq 0.6$ & \\
\hline & Very low (VL) & $0 \leq$ Vulnerability $\leq 0.3$ & \\
\hline
\end{tabular}

\subsection{The vulnerability assessment by the fuzzy model}

Firstly, a fuzzy model based on the Mamdani algorithm under Matlab environment is constructed to formulate the vulnerability assessment process. Therefore, the model contains three input components, including the contribution rate, resilience, and resistance, and one output (i.e. vulnerability index). Figure 6 shows the structure of the proposed model for the vulnerability assessment. In order to establish the fuzzy model, the data must be defined as a fuzzy set. The fuzzy definition of both input and output variables are illustrated in Table 2.

Likewise, two membership functions, including the contribution rate parameter and the vulnerability index, are graphically presented in Figures 7 and 8. The expert team generates 125 fuzzy rules for assessing the vulner- ability. Figure 9 shows a limited number of the fuzzy rules written in Matlab software environment. Table 3 lists the property of the fuzzy model established for the vulnerability assessment.

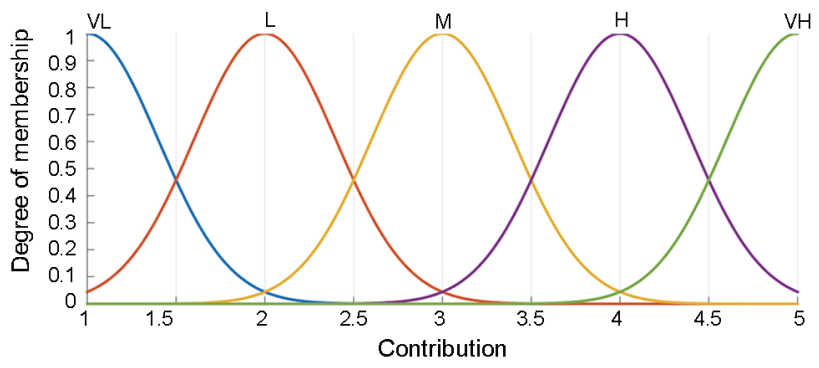

Figure 7. Membership function for the contribution rate parameter 


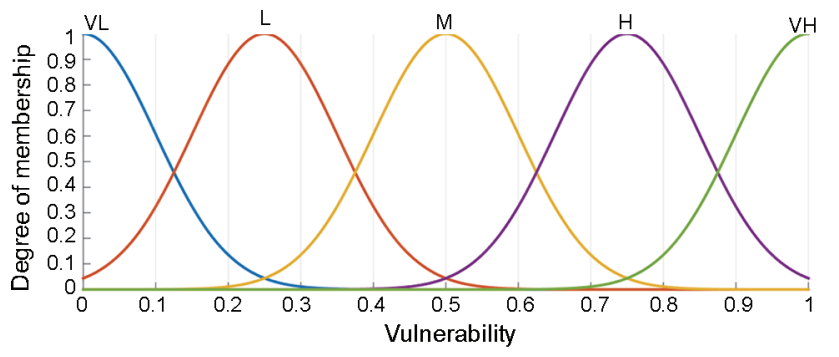

Figure 8. Membership function for the vulnerability parameter

Table 3. The features of the fuzzy model established for the Vulnerability index

\begin{tabular}{|c|c|}
\hline Name & Vulnerability \\
\hline Type & mamdani \\
\hline Inputs/Outputs & {$\left[\begin{array}{ll}3 & 1\end{array}\right]$} \\
\hline NumInputMFs & {$\left[\begin{array}{lll}5 & 5 & 5\end{array}\right]$} \\
\hline NumOutputMFs & 5 \\
\hline NumRules & 125 \\
\hline AndMethod & $\min$ \\
\hline OrMethod & $\max$ \\
\hline ImpMethod & $\min$ \\
\hline AggMethod & $\max$ \\
\hline DefuzzMethod & centroid \\
\hline \multirow[t]{3}{*}{ InLabels } & Contribution \\
\hline & Resilience \\
\hline & Resistance \\
\hline OutLabels & Vulnerability \\
\hline \multirow[t]{3}{*}{ InRange } & {$\left[\begin{array}{ll}1 & 5\end{array}\right]$} \\
\hline & {$\left[\begin{array}{ll}1 & 5\end{array}\right]$} \\
\hline & {$\left[\begin{array}{ll}1 & 5\end{array}\right]$} \\
\hline OutRange & {$\left[\begin{array}{ll}0 & 1\end{array}\right]$} \\
\hline
\end{tabular}

To analyze the interdependency between input and output variables, a sensitivity analysis tool, well-known as a control surface, is applied. Figure 10 shows how two input variables the contribution rate and resilience can impact the vulnerability index. This figure demonstrates there is a significant interdependency of vulnerability on contribution rate and resilience parameters.

\subsection{The consequence assessment by the fuzzy model}

In the second stage, in order to assess the consequence index, a fuzzy model based on the Mamdani algorithm under Matlab environment is constructed. This model also contains three input components, including time, cost, and quality, and one output (i.e. consequence index). The structure of the model for the consequence assessment is shown in Figure 11. As well as, the fuzzy definition of both input and output variables are illustrated in Table 4.

For better understanding, two membership functions time parameter and the consequence index are graphically presented in Figures 12 and 13. The expert team generates 125 fuzzy rules for the consequence assessment. Figures 14 and 15 show a limited number of the fuzzy rules written in Matlab software environment. Table 5 lists the property of the fuzzy model established for the consequence assessment. Figure 16 shows the interdependency of the consequence index on time and cost. From the figure, it can be obvious that a substantial interdependency of consequence on time and cost variables.

\subsection{Final evaluation of the overall risk index}

In the last stage of the proposed model, the overall risk index is calculated by a combination of the consequence and vulnerability indices derived from the two previous stages with the likelihood index resulted from experts' opinion

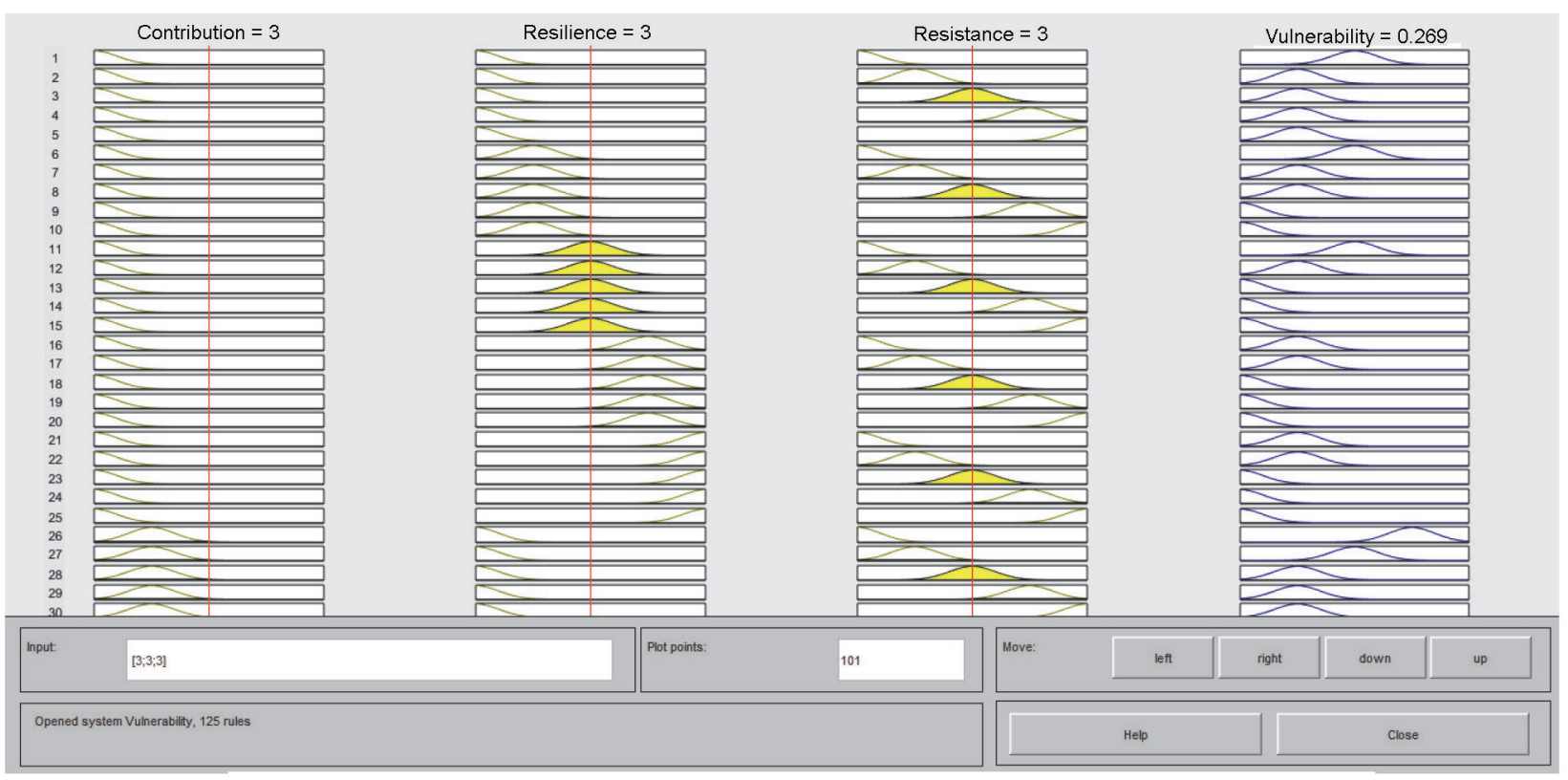

Figure 9. A graphical view of if-then rules 


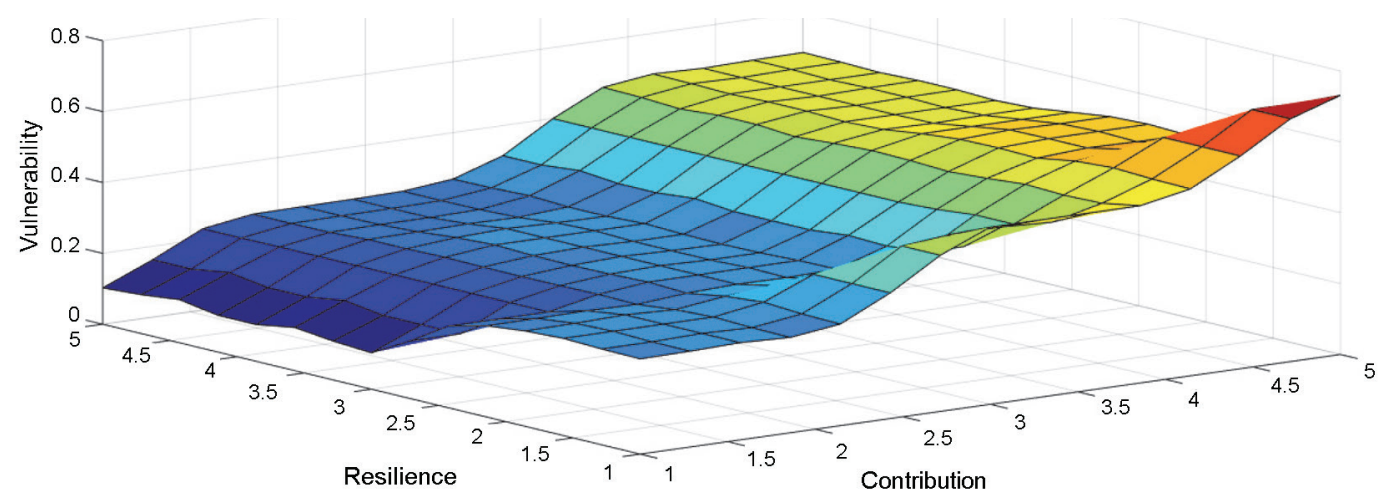

Figure 10. Control surface of vulnerability on contribution and resilience

Table 4. Fuzzy definition of input and output variables for the consequence assessment

\begin{tabular}{|c|c|c|c|}
\hline Factors & Linguistic term & Fuzzy ratings & Universe of discourse $(\mathrm{X})$ \\
\hline \multirow[t]{5}{*}{ Time } & Very High (VH) & $3.5 \leq$ Time $\leq 5$ & \multirow[t]{5}{*}{$\mathrm{X}_{\text {Time }} €(1,5)$} \\
\hline & $\operatorname{High}(\mathrm{H})$ & $2.5 \leq$ Time $\leq 5$ & \\
\hline & Medium (M) & $1.5 \leq$ Time $\leq 4.5$ & \\
\hline & Low (L) & $1 \leq$ Time $\leq 3.5$ & \\
\hline & Very Low (VL) & $1 \leq$ Time $\leq 2.5$ & \\
\hline \multirow[t]{5}{*}{ Cost } & Very High $(\mathrm{VH})$ & $3.5 \leq \operatorname{Cost} \leq 5$ & \multirow[t]{5}{*}{$X_{\text {Cost }} €(1,5)$} \\
\hline & $\operatorname{High}(\mathrm{H})$ & $2.5 \leq \operatorname{Cost} \leq 5$ & \\
\hline & Medium (M) & $1.5 \leq \operatorname{Cost} \leq 4.5$ & \\
\hline & Low (L) & $1 \leq \operatorname{Cost} \leq 3.5$ & \\
\hline & Very Low (VL) & $1 \leq \operatorname{Cost} \leq 2.5$ & \\
\hline \multirow[t]{5}{*}{ Quality } & Very High (VH) & $3.5 \leq$ Quality $\leq 5$ & \multirow[t]{5}{*}{$\mathrm{X}_{\text {Quality }} €(1,5)$} \\
\hline & $\operatorname{High}(\mathrm{H})$ & $2.5 \leq$ Quality $\leq 5$ & \\
\hline & Medium (M) & $1.5 \leq$ Quality $\leq 4.5$ & \\
\hline & Low (L) & $1 \leq$ Quality $\leq 3.5$ & \\
\hline & Very Low (VL) & $1 \leq$ Quality $\leq 2.5$ & \\
\hline \multirow[t]{5}{*}{ Consequence } & Very high $(\mathrm{VH})$ & $0.7 \leq$ Consequence $\leq 1.0$ & \multirow[t]{5}{*}{$X_{\text {Consequence }} €(0,1)$} \\
\hline & $\operatorname{High}(\mathrm{H})$ & $0.4 \leq$ Consequence $\leq 1.0$ & \\
\hline & Medium (M) & $0.2 \leq$ Consequence $\leq 0.8$ & \\
\hline & Low (L) & $0.0 \leq$ Consequence $\leq 0.6$ & \\
\hline & Very low (VL) & $0 \leq$ Consequence $\leq 0.3$ & \\
\hline
\end{tabular}




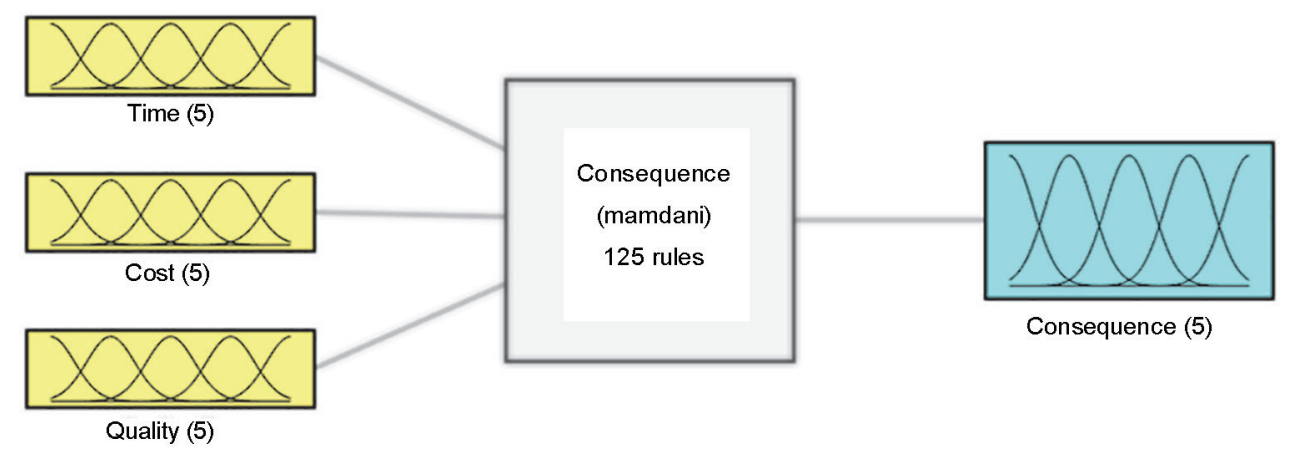

Figure 11. Structure of fuzzy model for the consequence assessment

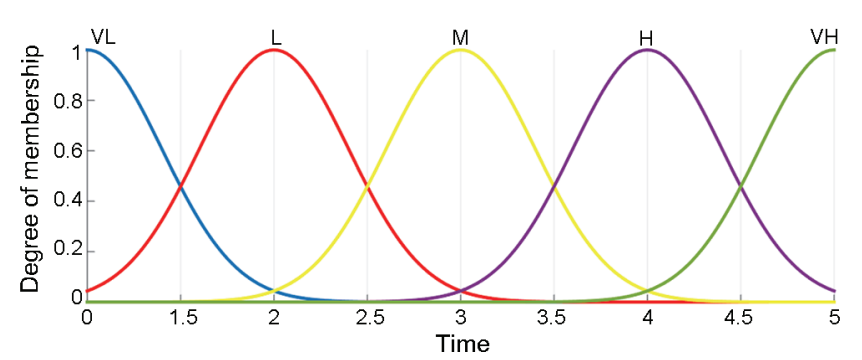

Figure 12. Membership function for the time parameter

Table 5. The features of the fuzzy model established for the consequence index

\begin{tabular}{|l|l|}
\hline \multicolumn{1}{|c|}{ Name } & Consequence \\
\hline Type & mamdani \\
\hline Inputs/Outputs & {$\left[\begin{array}{ll}3 & 1\end{array}\right]$} \\
\hline NumInputMFs & {$\left[\begin{array}{ll}5 & 5\end{array}\right]$} \\
\hline NumOutputMFs & 5 \\
\hline NumRules & 125 \\
\hline AndMethod & min \\
\hline OrMethod & max \\
\hline ImpMethod & min \\
\hline AggMethod & max \\
\hline DefuzzMethod & centroid \\
\hline InLabels & Time \\
\cline { 2 - 2 } & Cost \\
\cline { 2 - 2 } & Quality \\
\hline OutLabels & Consequence \\
\hline InRange & {$\left[\begin{array}{ll}15\end{array}\right]$} \\
\cline { 2 - 2 } & {$\left[\begin{array}{ll}15\end{array}\right]$} \\
\cline { 2 - 2 } & {$\left[\begin{array}{l}15 \\
\end{array}\right]$} \\
\hline OutRange & {$[01]$} \\
\hline
\end{tabular}

based on membership function given in Figure 17. These three input factors form the structure of the fuzzy model for assessing the risk index (as seen in Figure 18). Finally, the risk evaluation of projects is resulted from a combination of linguistic variables and fuzzy computations derived from the two previous stages. The risk index obtained by

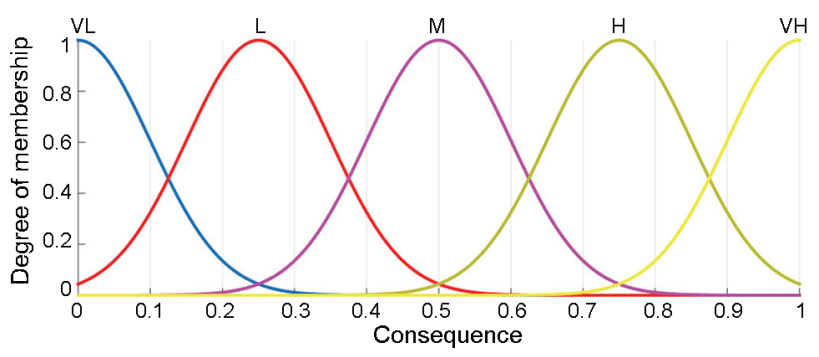

Figure 13. Membership function for the consequence index

the model is allocated to different projects for extracting the projects with high potential for failure and providing a proper scenario for risk planning. It is noted that the risk evaluation process is a dynamic procedure. This process should be always monitored and periodically re-evaluated. The fuzzy definitions of both input and output components are listed in Table 6 . For better understanding, the membership function for the risk index is schematically depicted in Figure 19. The features of the proposed model for the risk evaluation is presented in Table 7. Based on the expert opinion, 125 fuzzy if-then rules are generated to formulate the sophisticated pattern between input and output variables.

\subsection{Validation of the proposed model}

Validation is the task of demonstrating that the model is a reasonable representation of an actual system. This paper uses a comparison model to show the potential of the proposed model for project risk evaluation. Therefore, the conventional model developed by Vidal and Marle (2012) and Chapman (2014) is employed to evaluate the project risk. Table 8 presents the required input data of the conventional technique. The results of the proposed model and those of the conventional technique are presented in Table 9. From the table, it can be obvious that the outputs extracted from the proposed model is more adapted to the real situations. In other words, the proposed model considers the relative importance of the parameters. Whereas, the conventional technique takes into account same importance for all parameters. On the other hand, the proposed model has an intrinsic flexibility that 


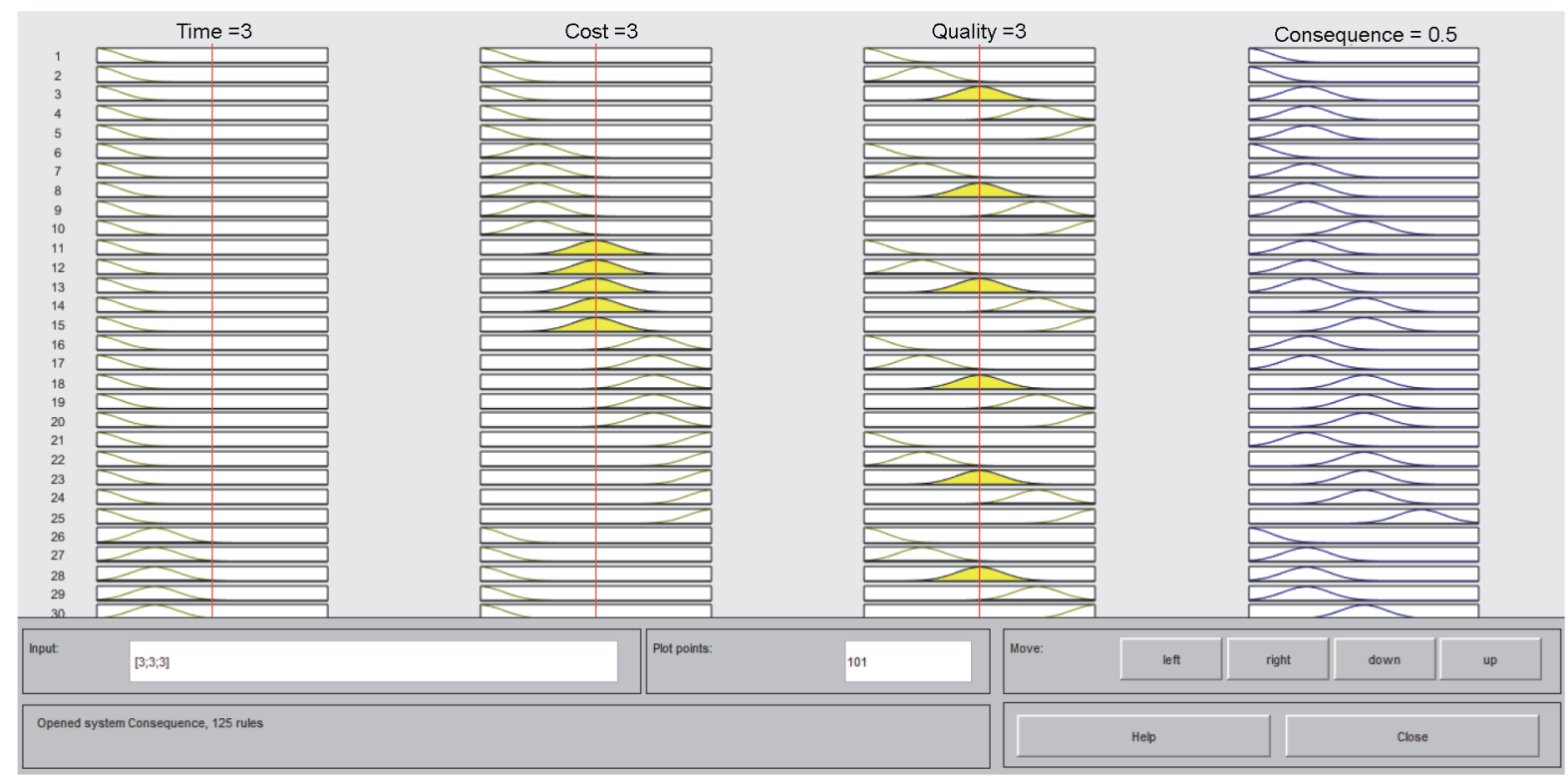

Figure 14. A graphical view of the rules for the consequence assessment

1. If (Time is VL) and (Cost is VL) and (Quality is VL) then (Consequence is VL) (1)

2. If (Time is VL) and (Cost is VL) and (Quality is L) then (Consequence is VL) (1)

3. If (Time is VL) and (Cost is VL) and (Quality is M) then (Consequence is L) (1)

4. If (Time is VL) and (Cost is VL) and (Quality is $\mathrm{H}$ ) then (Consequence is $\mathrm{L}$ ) (1)

5. If (Time is VL) and (Cost is VL) and (Quality is VH) then (Consequence is L) (1)

6. If (Time is VL) and (Cost is L) and (Quality is VL) then (Consequence is VL) (1)

7. If (Time is VL) and (Cost is $\mathrm{L}$ ) and (Quality is $\mathrm{L}$ ) then (Consequence is $\mathrm{L}$ ) (1)

8. If (Time is VL) and (Cost is L) and (Quality is M) then (Consequence is L) (1)

9. If (Time is VL) and (Cost is L) and (Quality is $\mathrm{H}$ ) then (Consequence is L) (1)

10. If (Time is VL) and (Cost is L) and (Quality is VH) then (Consequence is M) (1)

115. If (Time is VH) and (Cost is $\mathrm{M}$ ) and (Quality is VH) then (Consequence is $\mathrm{H}$ ) (1)

116. If (Time is VH) and (Cost is $\mathrm{H}$ ) and (Quality is VL) then (Consequence is M) (1)

117. If (Time is VH) and (Cost is $\mathrm{H}$ ) and (Quality is $\mathrm{L}$ ) then (Consequence is $\mathrm{H}$ ) (1)

118. If (Time is VH) and (Cost is $\mathrm{H}$ ) and (Quality is $\mathrm{M}$ ) then (Consequence is $\mathrm{H}$ ) (1)

119. If (Time is VH) and (Cost is $\mathrm{H}$ ) and (Quality is $\mathrm{H}$ ) then (Consequence is $\mathrm{H}$ ) (1)

120. If (Time is VH) and (Cost is $\mathrm{H}$ ) and (Quality is VH) then (Consequence is VH) (1)

121. If (Time is VH) and (Cost is VH) and (Quality is VL) then (Consequence is H) (1)

122. If (Time is $\mathrm{VH}$ ) and (Cost is $\mathrm{VH}$ ) and (Quality is $\mathrm{L}$ ) then (Consequence is $\mathrm{H}$ ) (1)

123. If (Time is VH) and (Cost is VH) and (Quality is $\mathrm{M}$ ) then (Consequence is $\mathrm{H}$ ) (1)

124. If (Time is VH) and (Cost is VH) and (Quality is $\mathrm{H}$ ) then (Consequence is VH) (1)

125. If (Time is VH) and (Cost is VH) and (Quality is VH) then (Consequence is VH) (1)

Figure 15. A part of the rules for the consequence assessment

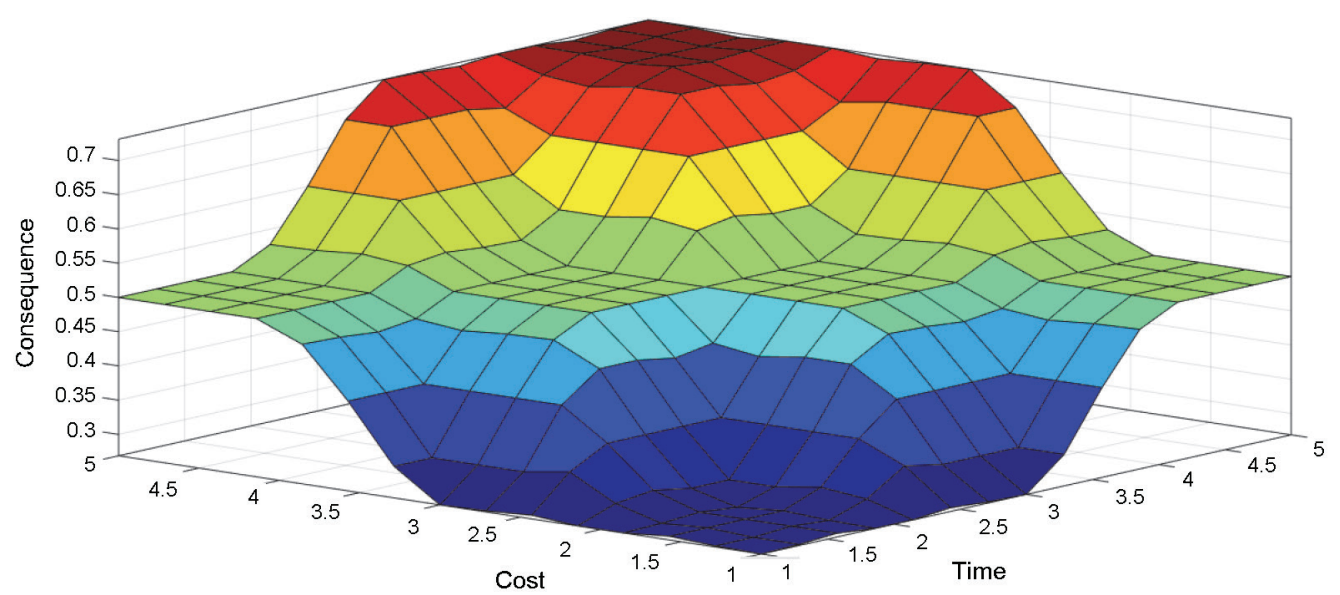

Figure 16. Control surface consequence on time and cost 
Table 6. Fuzzy definition of input and output variables for the risk evaluation

\begin{tabular}{|c|c|c|c|}
\hline Factors & Linguistic term & Fuzzy ratings & Universe of discourse (X) \\
\hline \multirow[t]{5}{*}{ Likelihood } & Very High (VH) & $3.5 \leq$ Likelihood $\leq 5$ & \multirow[t]{5}{*}{$\mathrm{X}_{\text {Likelihood }} €(1,5)$} \\
\hline & High $(\mathrm{H})$ & $2.5 \leq$ Likelihood $\leq 5$ & \\
\hline & Medium (M) & $1.5 \leq$ Likelihood $\leq 4.5$ & \\
\hline & Low (L) & $1 \leq$ Likelihood $\leq 3.5$ & \\
\hline & Very Low (VL) & $1 \leq$ Likelihood $\leq 2.5$ & \\
\hline \multirow[t]{5}{*}{ Vulnerability } & Very High (VH) & $0.7 \leq$ Vulnerability $\leq 1.0$ & \multirow[t]{5}{*}{$\mathrm{X}_{\text {Vulnerability }} €(1,5)$} \\
\hline & $\operatorname{High}(\mathrm{H})$ & $0.4 \leq$ Vulnerability $\leq 1.0$ & \\
\hline & Medium (M) & $0.2 \leq$ Vulnerability $\leq 0.8$ & \\
\hline & Low (L) & $0.0 \leq$ Vulnerability $\leq 0.6$ & \\
\hline & Very Low (VL) & $0 \leq$ Vulnerability $\leq 0.3$ & \\
\hline \multirow[t]{5}{*}{ Consequence } & Very High (VH) & $0.7 \leq$ Consequence $\leq 1.0$ & \multirow[t]{5}{*}{$\mathrm{X}_{\text {Consequence }} €(0,1)$} \\
\hline & $\operatorname{High}(\mathrm{H})$ & $0.4 \leq$ Consequence $\leq 1.0$ & \\
\hline & Medium (M) & $0.2 \leq$ Consequence $\leq 0.8$ & \\
\hline & Low (L) & $0.0 \leq$ Consequence $\leq 0.6$ & \\
\hline & Very Low (VL) & $0 \leq$ Consequence $\leq 0.3$ & \\
\hline \multirow[t]{5}{*}{ Risk } & Very high (VH) & $0.7 \leq$ Risk $\leq 1.0$ & \multirow[t]{5}{*}{$\mathrm{X}_{\text {Risk }} €(0,1)$} \\
\hline & High $(\mathrm{H})$ & $0.4 \leq$ Risk $\leq 1.0$ & \\
\hline & Medium (M) & $0.2 \leq$ Risk $\leq 0.8$ & \\
\hline & Low $(\mathrm{L})$ & $0.0 \leq$ Risk $\leq 0.6$ & \\
\hline & Very low (VL) & $0 \leq$ Risk $\leq 0.3$ & \\
\hline
\end{tabular}

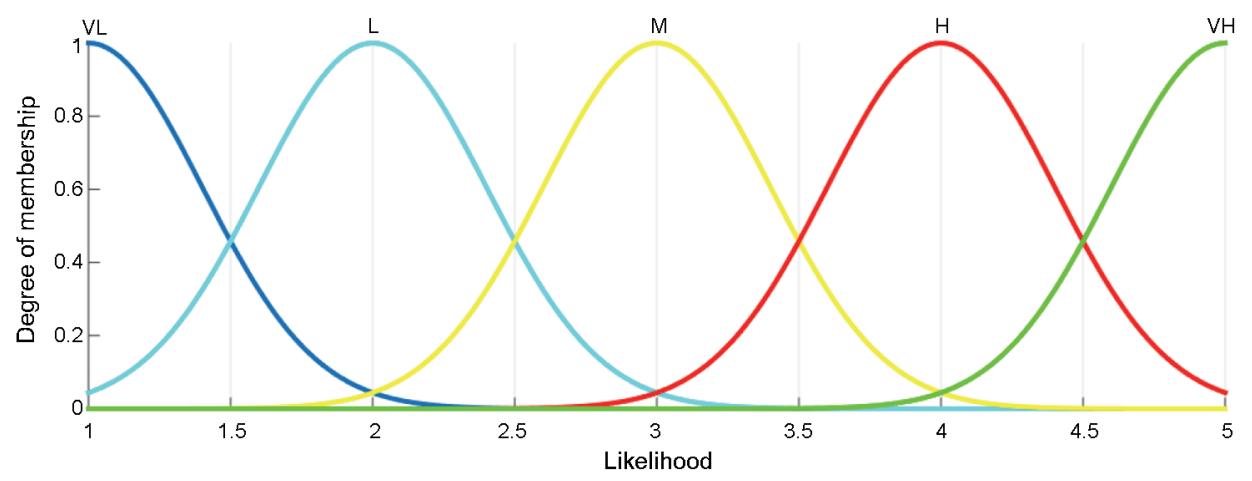

Figure 17. Membership function for the likelihood parameter 


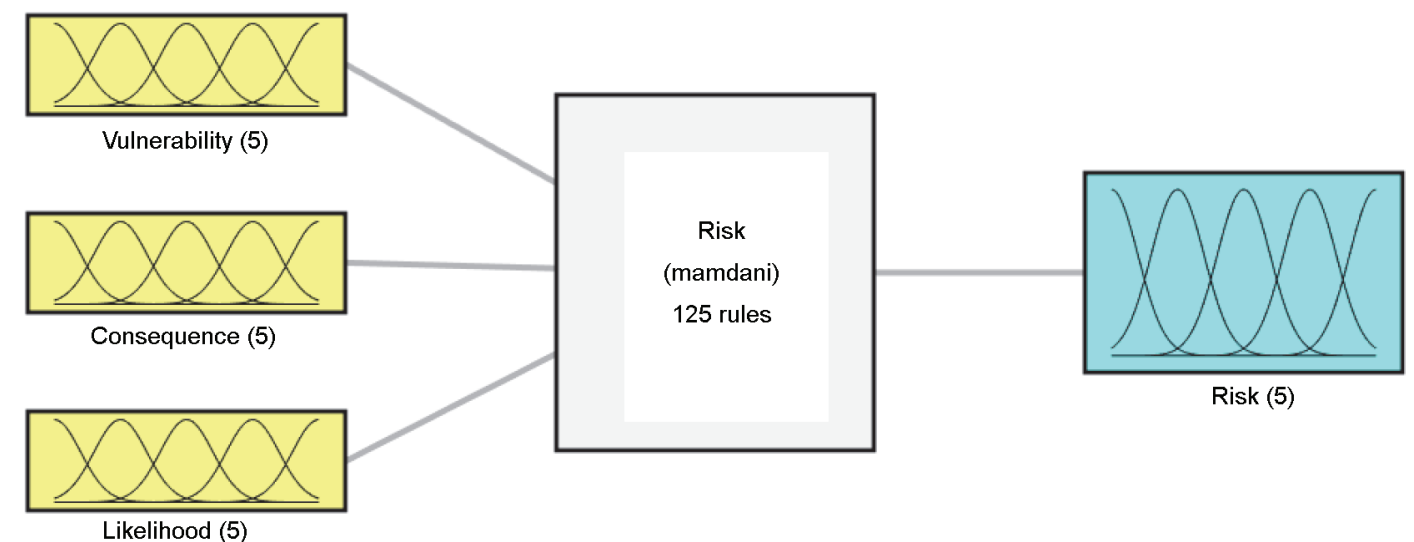

Figure 18. Structure of fuzzy model for risk evaluation

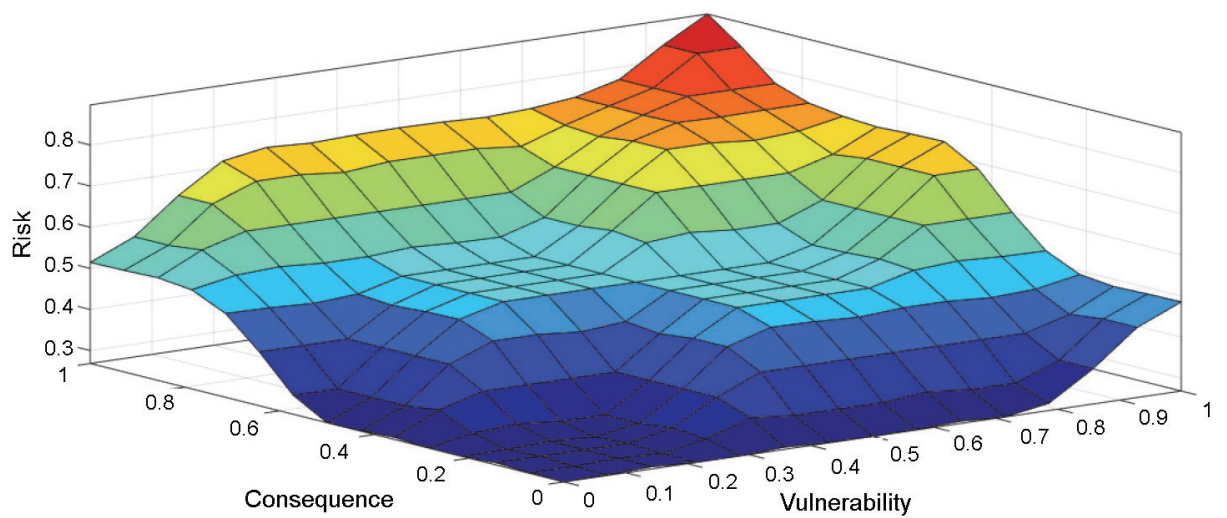

Figure 19. Control surface of risk on consequence and vulnerability

Table 7. The features of the fuzzy model established for the risk index

\begin{tabular}{|l|l|}
\hline \multicolumn{1}{|c|}{ Name } & \multicolumn{1}{c|}{ Risk } \\
\hline Type & mamdani \\
\hline Inputs/Outputs & {$\left[\begin{array}{ll}3 & 1\end{array}\right]$} \\
\hline NumInputMFs & {$\left[\begin{array}{ll}5 & 5\end{array}\right]$} \\
\hline NumOutputMFs & 5 \\
\hline NumRules & 125 \\
\hline AndMethod & min \\
\hline OrMethod & max \\
\hline ImpMethod & min \\
\hline AggMethod & max \\
\hline DefuzzMethod & centroid \\
\hline InLabels & Vulnerability \\
\cline { 2 - 3 } & Consequence \\
\cline { 2 - 3 } & Likelihood \\
\hline OutLabels & Risk \\
\hline InRange & {$\left[\begin{array}{ll}0 & 1\end{array}\right]$} \\
\cline { 2 - 3 } & {$\left[\begin{array}{ll}0 & 1\end{array}\right]$} \\
\cline { 2 - 2 } & {$\left[\begin{array}{ll}1 & 5\end{array}\right]$} \\
\hline OutRange & {$\left[\begin{array}{ll}0 & 1\end{array}\right]$} \\
\hline & \\
\hline
\end{tabular}

Table 8. The required input data of the conventional model

\begin{tabular}{|cllll|}
\hline $\begin{array}{c}\text { Crisp } \\
\text { rating }\end{array}$ & Vulnerability & Consequence & Likelihood & Risk \\
\hline 1 & $\begin{array}{l}\text { Not } \\
\text { vulnerable }\end{array}$ & Negligible & Negligible & Negligible \\
\hline 2 & Low & Low & Low & Low \\
\hline 3 & Medium & Medium & Medium & Medium \\
\hline 4 & High & High & High & High \\
\hline 5 & Very high & Very high & Very high & Very high \\
\hline
\end{tabular}

can overcome the shortages and limitations of the conventional model and improve the precision of the results. This leads to a systematic error in the results of the conventional technique; so that, the risk index for project 1 is equal to projects 2, 5, 5, and 7. Whereas, these projects have different levels of the risk. Therefore, this error wastes the financial and human resources.

\section{Conclusions}

Risk evaluation plays a key role in project risk management. From a purely technical viewpoint, different guidelines for decision-makers about how to deal with hazardous events are developed. However, there is not a 
Table 9. The results of the models

\begin{tabular}{|c|c|c|c|c|c|c|c|c|c|c|}
\hline & \multicolumn{5}{|c|}{ The Conventional model } & \multicolumn{5}{|c|}{ The proposed model } \\
\hline & 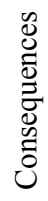 & 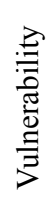 & 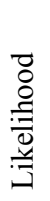 & $\frac{y}{a n}$ & $\underset{\check{Z}}{\check{Z}}$ & 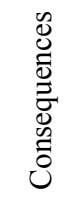 & 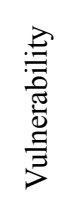 & 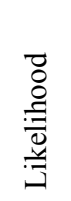 & $\frac{y}{a}$ & $\begin{array}{l}\text { 壳 } \\
\text { ॥ }\end{array}$ \\
\hline Project 1 & 2 & 3 & 1 & 2 & 3 & 0.38 & 0.55 & 1.1 & 0.384 & 5 \\
\hline Project 2 & 3 & 1 & 2 & 2 & 3 & 0.62 & 0.07 & 2 & 0.329 & 7 \\
\hline Project 3 & 4 & 3 & 2 & 3 & 2 & 0.77 & 0.62 & 2.2 & 0.616 & 2 \\
\hline Project 4 & 1 & 4 & 3 & 2 & 3 & 0.21 & 0.83 & 2.8 & 0.568 & 4 \\
\hline Project 5 & 2 & 2 & 2 & 2 & 3 & 0.42 & 0.36 & 2.1 & 0.358 & 6 \\
\hline Project 6 & 3 & 5 & 4 & 4 & 1 & 0.59 & 0.78 & 3.8 & 0.697 & 1 \\
\hline Project 7 & 3 & 3 & 1 & 2 & 3 & 0.64 & 0.60 & 2.05 & 0.596 & 3 \\
\hline
\end{tabular}

well-defined instruction to logically evaluate the level of risk and absolutely eliminate the hazardous phenomena. On the other hand, designers and managers are confronted with an ill-defined problem, generally arising from the inability to quantify many losses and technical or financial limitations on data gathering. Therefore, there is a cogent reason to develop a model based on the project risk evaluation as a potential threat to the organization and to find some solutions for reducing or eliminating the undesirable consequences in the future.

The Elena guideline provides a flexible approach to process both objective and subjective input data. This guideline provides a risk evaluation methodology for a broad variety of operational activities. However, the merit of using a fuzzy system to handle the uncertainty imposed by projects. This technique helps managers to formulate a problem by using natural language.

This paper proposes a three-stage procedure based on the fuzzy inference system under the environment of the Elena guideline. The first stage employs three components the contribution rate, resilience, and resistance to assess the vulnerability index. The second stage uses three parameters time, cost, and quality to assess the consequence index. Finally, the risk index is evaluated by combining the outputs derived from the vulnerability and consequence indices with output resulted from experts' opinion based on the given fuzzy set. To demonstrate the potential application of the proposed model, a case study, namely Rah Gostar Naft Company, is illustrated and investigated. The results show that the performance of the proposed model is better in comparison with those of the conventional technique. Based on the results, the proposed model proposes a comprehensive analysis of the risky projects and the company can eliminate or reduce the projects with high potential for damage. However, the proposed model employs both objective and subjective data in a coherent way. Likewise, the model takes into account the relative impor- tance of the influencing factors. Nevertheless, the model developed in this paper supports the full cycle of the risk management process (including risk identification, risk evaluation, risk planning, and risk monitoring), which is a key for the improvement of portfolio performance.

\section{References}

Akintoye, A. S.; MacLeod, M. J. 1997. Risk analysis and management in construction, International Journal of Project Management $15(1)$ : $31-38$.

https://doi.org/10.1016/S0263-7863(96)00035-X

AS/NZS 4360 Risk management. Standards Australia, Sydney, NSW, 2004.

Badri, A.; Nadeau, S.; Gbodossou, A. 2012. Proposal of a riskfactor-based analytical approach for integrating occupational health and safety into project risk evaluation, Accident Analysis \& Prevention 48: 223-234. https://doi.org/10.1016/j.aap.2011.05.009

Cano, A.; Cruz, M. P. 2002. Integrated methodology for project risk management, Journal of Construction Engineering and Management 128: 473-485.

https://doi.org/10.1061/(ASCE)0733-9364(2002)128:6(473)

Carbone, T. A.; Tippett, D. D. 2004. Project risk management using the project risk FMEA, Engineering Management Journal 16(4): 28-35. https://doi.org/10.1080/10429247.2004.11415263

Carvalho, M. M.; Junior, R. R. 2015. Impact of risk management on project performance: the importance of soft skills, International Journal of Production Research 53(2): 321-340. https://doi.org/10.1080/00207543.2014.919423

Chapman, C. 1997. Project risk analysis and managementPRAM the generic process, International Journal of Project Management 15(5): 273-281.

https://doi.org/10.1016/S0263-7863(96)00079-8

Chapman, C. B. 1990. A risk engineering approach to project risk management, Risk Management 8(1): 5-16. https://doi.org/10.1016/0263-7863(90)90003-T

Chapman, R. J. 2014. The rules of project risk management: Implementation guidelines for major projects. Gower. 
Chatterjee, K.; Zavadskas, E. K.; Tamošaitienė, J.; Adhikary, K.; Kar, S. 2018. A Hybrid MCDM technique for risk management in construction projects, Symmetry 10(2): 46. https://doi.org/10.3390/sym10020046

Cooper, D. F.; Grey, S.; Raymond, G.; Walker, P. 2005. Project risk management guidelines: Managing risk in large projects and complex procurements. John Wiley \& Sons Ltd.

Dey, P. K. 2002. Project risk management: A combined analytic hierarchy process and decision tree approach, Cost Engineering 44(3): 13-26.

Dey, P. K. 2010. Managing project risk using combined analytic hierarchy process and risk map, Applied Soft Computing 10(4): 990-1000. https://doi.org/10.1016/j.asoc.2010.03.010

Dey, P. K. 2012. Project risk management using multiple criteria decision-making technique and decision tree analysis: a case study of Indian oil refinery, Production Planning \& Control 23(12): 903-921. https://doi.org/10.1080/09537287.2011.586379

Ebrat, M.; Ghodsi, R. 2014. Construction project risk assessment by using adaptive-network-based fuzzy inference system: An empirical study, KSCE Journal of Civil Engineering 18(5): 1213-1227. https://doi.org/10.1007/s12205-014-0139-5

El-Razek, M. E. A.; Bassioni, H. A.; Mobarak, A. M. 2008. Causes of delay in building construction projects in Egypt, Journal of Construction Engineering and Management 134(11): 831-841. https://doi.org/10.1061/(ASCE)0733-9364(2008)134:11(831)

Endut, I. R.; Shehu, Z.; Akintoye, A.; Jaafar, A. 2009. Cost and time of construction projects in Malaysia, in Fifth International Conference on Construction in the $21^{\text {st }}$ Century (CITC-V) "Collaboration and Integration in Engineering, Management and Technology”, 20-22 May 2009, Istanbul, Turkey.

Fouladgar, M. M.; Yazdani-Chamzini, A.; Zavadskas, E. K. 2012. Risk evaluation of tunneling projects, Archives of Civil and Mechanical Engineering 12(1): 1-12. https://doi.org/10.1016/j.acme.2012.03.008

Hashemi, H.; Mousavi, S. M.; Mojtahedi, S. M. H. 2011. Bootstrap technique for risk analysis with interval numbers in bridge construction projects, Journal of Construction Engineering and Management 137: 600-608. https://doi.org/10.1061/(ASCE)CO.1943-7862.0000344

Hillson, D.; Grimaldi, S.; Rafele, C. 2006. Managing project risks using a cross risk breakdown matrix, Risk Management 8(1): 61-76. https://doi.org/10.1057/palgrave.rm.8250004

Hu, A. H.; Hsu, C. W.; Kuo, T. C.; Wu, W. C. 2009. Risk evaluation of green components to hazardous substance using FMEA and FAHP, Expert Systems with Applications 36(3): 7142-7147. https://doi.org/10.1016/j.eswa.2008.08.031

IEC 62198 Project risk management - Application guidelines. International Electrotechnical Commission, 2001.

Ilbahar, E.; Karaşan, A.; Cebi, S.; Kahraman, C. 2018. A novel approach to risk assessment for occupational health and safety using Pythagorean fuzzy AHP \& fuzzy inference system, Safety Science 103: 124-136.

Iqbal, S.; Choudhry, R. M.; Holschemacher, K.; Ali, A., Tamošaitiene, J. 2015. Risk management in construction projects, Technological and Economic Development of Economy 21(1): 65-78. https://doi.org/10.3846/20294913.2014.994582

Jamshidi, A.; Yazdani-Chamzini, A.; Yakhchali, S. H.; Khaleghi, S. 2013. Developing a new fuzzy inference system for pipeline risk assessment, Journal of Loss Prevention in the Process Industries 26(1): 197-208.

https://doi.org/10.1016/j.jlp.2012.10.010
Keramati, A.; Nazari-Shirkouhi, S.; Moshki, H.; Afshari-Mofrad, M.; Maleki-Berneti, E. 2013a. A novel methodology for evaluating the risk of CRM projects in fuzzy environment, Neural Computing and Applications 23(Suppl 1): S29-S53. https://doi.org/10.1007/s00521-012-1216-7

Keramati, A.; Samadi, H.; Nazari-Shirkouhi, S. 2013b. Managing risk in information technology outsourcing: an approach for analysing and prioritising using fuzzy analytical network process, International Journal of Business Information Systems 12(2): 210-242. https://doi.org/10.1504/IJBIS.2013.052052

Lee, E. M.; Jones, D. K. C. 2004. Landslide risk assessment. Thomas Telford Limited. https://doi.org/10.1680/lra.31715

Licata, G. 2012. Fuzzy logic, knowledge and natural language, in M. F. Azeem (Ed.). Fuzzy inference system - theory and applications. InTech, 3-18.

Liu, H. C.; Liu, L.; Liu, N.; Mao, L. X. 2012. Risk evaluation in failure mode and effects analysis with extended VIKOR method under fuzzy environment, Expert Systems with Applications 39(17): 12926-12934.

https://doi.org/10.1016/j.eswa.2012.05.031

Liu, J.; Li, Q.; Wang, Y. 2013. Risk analysis in ultra deep scientific drilling project - A fuzzy synthetic evaluation approach, International Journal of Project Management 31: 449-458. https://doi.org/10.1016/j.ijproman.2012.09.015

Liu, P.; Zhang, X.; Liu, W. 2011. A risk evaluation method for the high-tech project investment based on uncertain linguistic variables, Technological Forecasting \& Social Change 78: 40-50. https://doi.org/10.1016/j.techfore.2010.04.011

Loch, C. H.; DeMeyer, A.; Pich, M. 2006. Managing the unknown: A new approach to managing high uncertainty and risk in projects. John Wiley \& Sons, Inc. https://doi.org/10.1002/9780470172377

Marcelino-Sádaba, S.; Pérez-Ezcurdia, A.; Lazcano, A. M. E.; Villanueva, P. 2014. Project risk management methodology for small firms, International Journal of Project Management 32(2): 327-340. https://doi.org/10.1016/j.ijproman.2013.05.009

Moura, H. P.; Teixeira, J. C.; Pires, B. 2007. Dealing with cost and time in the Portuguese construction industry, in CIB World Building Congress, 1252-1265.

Nieto-Morote, A.; Ruz-Vila, F. 2011. A fuzzy approach to construction project risk assessment, International Journal of Project Management 29(2): 220-231.

https://doi.org/10.1016/j.ijproman.2010.02.002

Office of Government Commerce (OGC). 2002. Management of risk: Guidance for practitioners. London: The Stationery Office.

Omoregie, A.; Radford, D. 2006. Infrastructure delays and cost escalation: causes and effects in Nigeria, in Proceedings of Sixth International Postgraduate Research Conference, 2006, Delft University of Technology, Netherlands, 79-93.

PMI. 2003. Project management body of knowledge (PMBOK). Chapter 11, in Risk management. Upper Darby, PA: Project Management Institute.

Razani, M.; Yazdani-Chamzini, A.; Yakhchali, S. H. 2013. A novel fuzzy inference system for predicting roof fall rate in underground coal mines, Safety Science 55: 26-33. https://doi.org/10.1016/j.ssci.2012.11.008

Rikhtegar, N.; Mansouri, N.; Oroumieh, A. A.; Yazdani-Chamzini, A.; Zavadskas, E. K.; Kildienè, S. 2014. Environmental impact assessment based on group decision-making methods in mining projects, Economic Research - Ekonomska Istraživanja 27(1): 378-392.

https://doi.org/10.1080/1331677X.2014.966971 
Samadi, H.; Nazari-Shirkouhi, S.; Keramati, A. 2014. Identifying and analyzing risks and responses for risk management in information technology outsourcing projects under fuzzy environment, International Journal of Information Technology \& Decision Making 13(6): 1283-1323. https://doi.org/10.1142/S021962201450076X

Schieg, M. 2006. Risk management in construction project management, Journal of Business Economics and Management 7(2): 77-83.

Shroder, J. F.; Davies, T. 2015. Landslide hazards, risks, and disasters. Hazards and Disasters Series, Elsevier Inc.

Tah, J. H. M.; Carr, V. 2000. A proposal for construction project risk assessment using fuzzy logic, Construction Management and Economics 18(4): 491-500. https://doi.org/10.1080/01446190050024905

Tamošaitienė, J.; Turskis, Z.; Zavadskas, E. K. 2008. Modeling of contractor selection taking into account different risk level, in The $25^{\text {th }}$ International Symposium on Automation and Robotics in Construction (ISARC 2008), 26-29 June 2008, Vilnius, Lithuania, 676-681.

Tamošaitienė, J.; Zavadskas, E. K.; Turskis, Z. 2013. Multi-criteria risk assessment of a construction project, in Procedia Computer Science: First International Conference on Information Technology and Quantitative Management (ITQM 2013), 16-18 May 2013, Suzhou, China, 17: 129-133.

TBC. 2001. Integrated risk management framework. Cat. No. BT22-78/2001 [online], [cited 12 May 2018]. Available from Internet: http://www.canada.ca/en/treasury-board-secretariat/corporate/risk-management/guide-integrated-risk-management.html

Tseng, C. L.; Lin, K. Y.; Sundararajan, S. K. 2005. Managing cost overrun risk in project funding allocation, Annals of Operations Research 135: 127-153. https://doi.org/10.1007/s10479005-6238-4

Tüysüz, F.; Kahraman, C. 2006. Project risk evaluation using a fuzzy analytic hierarchy process: An application to information technology projects, International Journal of Intelligent Systems 21: 559-584. https://doi.org/10.1002/int.20148

Valipour, A.; Yahaya, N.; Noor, N. M.; Mardani, A.; Antuchevičienè, J. 2016. A new hybrid fuzzy cybernetic analytic network process model to identify shared risks in PPP projects, International Journal of Strategic Property Management 20(4): 409-426. https://doi.org/10.3846/1648715X.2016.1210547

Vidal, L. A.; Marle, F. 2012. A systems thinking approach for project vulnerability management, Kybernetes 41(1/2): 206228. https://doi.org/10.1108/03684921211213043

Vrijling, J. K.; Hengel, W.; Houben, R. J. 1995. A framework for risk evaluation, Journal of Hazardous Materials 43: 245-261. https://doi.org/10.1016/0304-3894(95)91197-V

Wang, S. Q.; Dulaimi, M. F.; Aguria, M. Y. 2004. Risk management framework for construction projects in developing countries, Construction Management and Economics 22(3): 237-252. https://doi.org/10.1080/0144619032000124689

Xu, Y.; Yeung, J. F. Y.; Chan, A. P. C.; Chan, D. W. M.; Wang, S. Q.; Ke, Y. 2010. Developing a risk assessment model for PPP projects in China - A fuzzy synthetic evaluation approach, Automation in Construction 19(7): 929-943. https://doi.org/10.1016/j.autcon.2010.06.006

Yakhchali, S. H. 2014. Elena project guideline. Iran: OBOUR Press.
Yazdani-Chamzini, A. 2014. Proposing a new methodology based on fuzzy logic for tunnelling risk assessment, Journal of Civil Engineering and Management 20(1): 82-94. https://doi.org/10.3846/13923730.2013.843583

Yazdani-Chamzini, A.; Yakhchali, S. H.; Mahmoodian, M. 2013. Risk ranking of tunnel construction projects by using the ELECTRE technique under a fuzzy environment, International Journal of Management Science and Engineering Management 8(1): 1-14.

Zadeh, L. A. 1965. Fuzzy sets, Information and Control 8(3): 338-353. https://doi.org/10.1016/S0019-9958(65)90241-X

Zavadskas, E. K.; Turskis, Z.; Tamošaitienè, J. 2008. Construction risk assessment of small scale objects by applying TOPSIS method with attributes values determined at intervals, in The $8^{\text {th }}$ International Conference "Reliability and Statistics in Transportation and Communication" (RelStat-08), 15-18 October 2008, Riga, Latvia, 351-357.

Zavadskas, E. K.; Turskis, Z.; Tamošaitiene, J. 2010. Risk assessment of construction projects, Journal of Civil Engineering and Management 16(1): 33-46. https://doi.org/10.3846/jcem.2010.03

Zeng, J.; An, M.; Smith, N. J. 2007. Application of a fuzzy based decision making methodology to construction project risk assessment, International Journal of Project Management 25(6): 589-600. https://doi.org/10.1016/j.ijproman.2007.02.006

Zou, P. X. W.; Zhang, G. 2009. Managing risks in construction projects: Life cycle and stakeholder perspectives, International Journal of Construction Management 9(1): 61-77. https://doi.org/10.1080/15623599.2009.10773122 